\title{
Stenotic bridging bronchus: A very rare entity
}

\author{
Salih Topcu, MD, ${ }^{a}$ Serife Tuba Liman, MD, ${ }^{a}$ Hasan Tahsin Sarisoy, MD, ${ }^{b}$ Abdulkadir Babaoglu, MD, ${ }^{c}$ and \\ Emre Ozker, MD, ${ }^{d}$ Kocaeli, Turkey
}

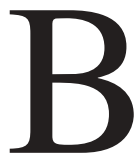

ridging bronchus $(\mathrm{BB})$ is one of the rarely seen congenital anomalies. BB is generally associated with other congenital anomalies, especially vascular anomalies. Congenital tracheal stenosis (CTS) is also seen rarely. Here we present a patient with a stenotic BB and bronchus suis anomaly.

\section{Clinical Summary}

A 10-month-old boy was admitted to the hospital with the complaints of respiratory distress and cough. He had wheezing since he was 2 months old. He had been given antimicrobial and bronchodilator treatment several times for bronchiolitis, but the symptoms had recurred frequently.

From the Departments of Thoracic Surgery, ${ }^{\mathrm{a}}$ Radiology, ${ }^{\mathrm{b}}$ Pediatric Cardiology, ${ }^{\mathrm{c}}$ and Cardiovascular Surgery, ${ }^{\mathrm{d}}$ The Faculty of Medicine, Kocaeli University, Kocaeli, Turkey.

Received for publication Dec 2, 2005; accepted for publication Jan 13 , 2006.

Address for reprints: Serife Tuba Liman, MD, Gogus Cerrahisi AD, Kocaeli Universitesi Tip Fakultesi, Umuttepe Kocaeli, Turkey (E-mail: tubaliman@ kou.edu.tr).

J Thorac Cardiovasc Surg 2006;131:1200-1

$0022-5223 / \$ 32.00$

Copyright $\odot 2006$ by The American Association for Thoracic Surgery doi:10.1016/j.jtcvs.2006.01.011
After medical treatment, his complaints were improved but recurred on his 10th day of hospitalization in our hospital. Chest radiography and thorax tomography revealed an abnormal branching and stenosis of the bronchial tree (Figure 1, A-C). Threedimensional computed tomographic (CT) imaging was performed, and it demonstrated that there was a carina formed by a right upper lobe bronchus (bronchus suis) and a stenotic BB (Figure 1,D). The stenotic BB connected with the residual carina formed by the left main bronchus and the remainder of the right main bronchus (right middle lobe and lower lobe bronchus). It was almost $15 \mathrm{~mm}$ long. Thorax magnetic resonance (MR) and MR angiography revealed no vascular anomaly and confirmed BB. The results of abdominal ultrasonography were normal. Echocardiography showed a small secundum-type atrial septal defect $(3.2 \mathrm{~mm}$ in diameter). After achievement of general anesthesia, rigid bronchoscopy was performed. The stenotic BB was almost $2 \mathrm{~mm}$ in diameter, and an optic device could not be passed through the BB.

Posterolateral thoracotomy was performed. Cardiopulmonary bypass (CPB) was not needed because of the absence of additional vascular anomalies. The stenotic BB was divided, and the left main bronchus was intubated from the operation field (Figure 2, $A$ and $B$ ). The stenotic BB was excised, and the junction of the trachea and the right upper lobe bronchus was anastomosed to the residual carina (Figure 2,C). The intercostal muscle flap was used for buttressing the anastomosis. In the preoperative or postoperative period tracheostomy was not needed. Pathologic examination of

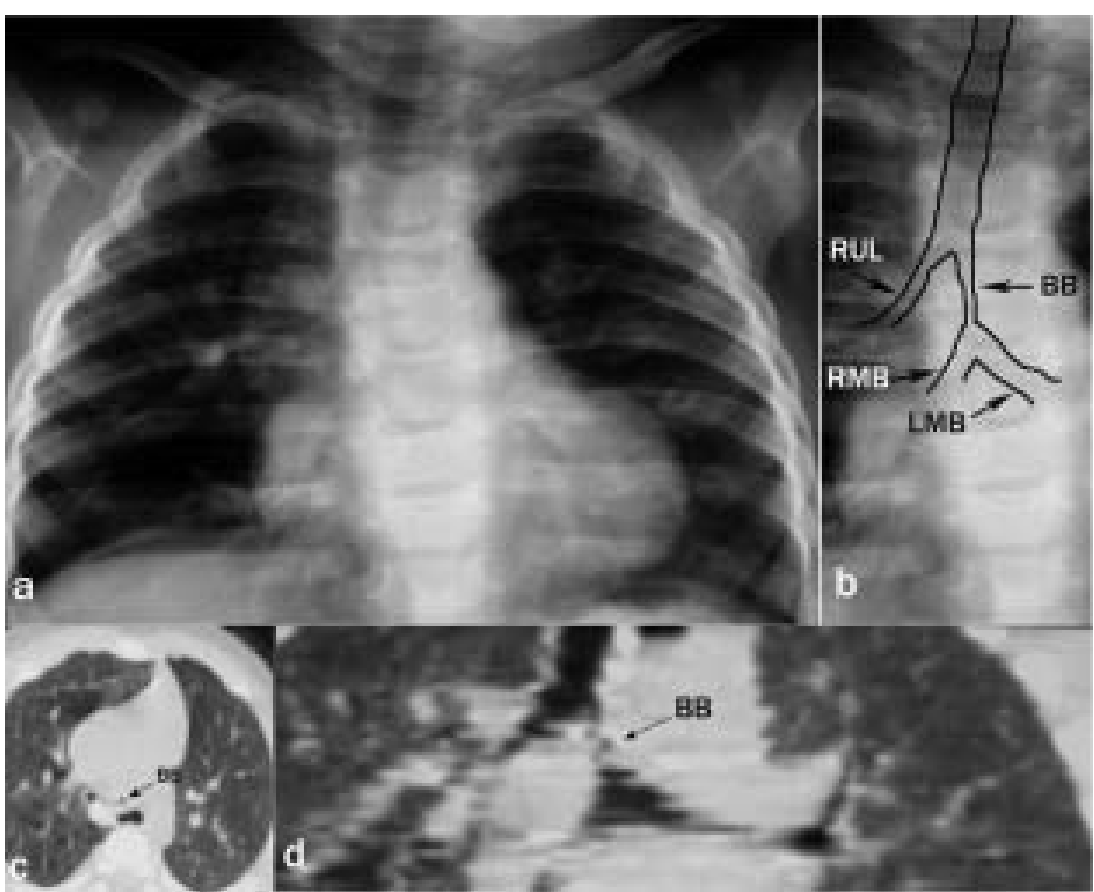

Figure 1. a and b, Digital posterolateral chest radiograph, with an air column showing 2 carina. $c$ and d, CT-MPR images displaying stenotic bridging bronchus. $B B$, Bridging bronchus; $R U L$, right upper lobe bronchus; $R M B$ right main bronchus; $L M B$, left main bronchus. 


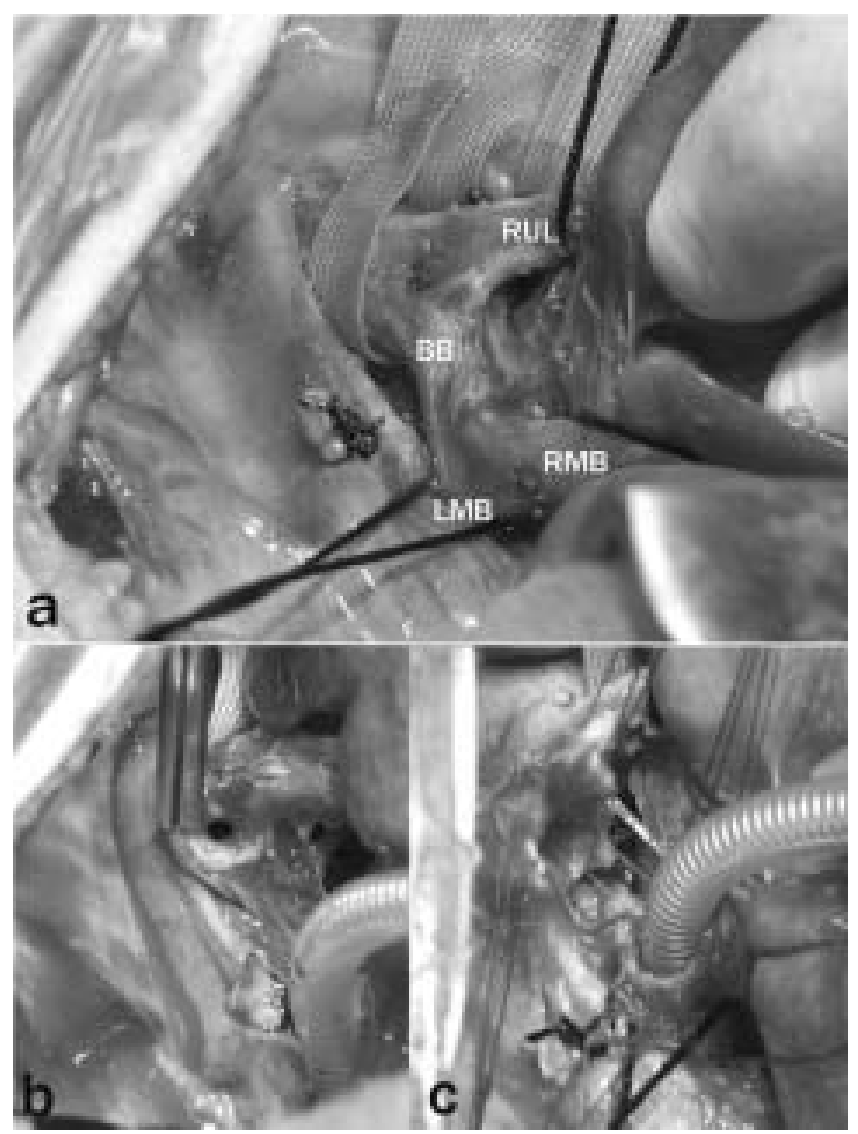

Figure 2. a, Posterolateral thoracotomy. Operation field: bridging bronchus was seen between the trachea and residual carina. b and c, Appearance after divided stenotic bridging bronchus. Its diameter was $2 \mathrm{~mm}$, and primary end-to-end anastomosis was present. $B B$, Bridging bronchus; $R U L$, right upper lobe bronchus; $R M B$, right main bronchus; $L M B$, left main bronchus.

the excised stenotic trachea revealed O-shaped tracheal rings. Ventilatory treatment was not needed. No complication was observed in the postoperative period. The patient was discharged from the hospital on his eighth postoperative day. He is in his 6-month follow-up period without any symptoms.

\section{Discussion}

Gonzalez-Crussi and colleagues ${ }^{1}$ first described $\mathrm{BB}$ as a right lower lobe bronchus (often with a middle lobe bronchus) arising from the left main bronchus and bridging the lower mediastinum. However, Grillo and associates ${ }^{2,3}$ described the BB differently. They named the BB as the bronchus between the trachea and the residual carina between the right and left main bronchus. They reported 2 patients with stenotic BB very similar to that seen in our patient. $^{2,3}$ That is why we chose Grillo's definition.

BB is extremely rare. This anomaly is associated with an anomalous right upper lobe bronchus (bronchus suis). Rishavy and coworkers ${ }^{4}$ reported that there were only 8 cases until 2001 in the English-language literature. BB might be associated with stenosis or bronchomalasia and cardiac or vascular anomalies. In our patient an atrial septal defect was detected.

BB without cardiovascular pathology might be asymptomatic, but CTS can cause varying degrees of respiratory distress, wheezing, coughing, stridor, apnea, cyanosis, and life-threatening airway obstruction. Persistent atelectasis and recurrent pneumonia can be seen.

Chest radiographic examinations are usually not helpful in congenital tracheobronchial anomalies. Spiral CT-MPR (multiplanar reconstruction) provides a good anatomic delineation of the airway in those cases. According to our experience, bronchoscopy and CT-MPR are enough to determine the anomaly in the tracheobronchial tree. Bronchography is not needed. MR and echocardiography are usually sufficient for evaluation of additional cardiovascular anomalies.

$\mathrm{CPB}$ might be needed if there are additional cardiac anomalies. Some authors recommend CPB in all CTS corrections, but the conduct of the operation is simplified by avoiding $\mathrm{CPB}{ }^{2}$

In conclusion, BB with or without stenosis should be kept in mind in infants and children with respiratory symptoms that cannot be healed with proper medical treatment. Spiral CT-MPR is very useful for determining the morphologic anomaly of the tracheobronchial tree.

\section{References}

1. Gonzalez-Crussi F, Padilla LM, Miller JK, Grosfeld JL. "Bridging bronchus": a previously undescribed airway anomaly. Am J Dis Child. 1976;130:1015-8.

2. Grillo HC. Tracheoplasty for congenital tracheal stenosis. Repair of congenital tracheal lesions. In: Grillo HC, editor. Surgery of the trachea and bronchi. Hamilton: BC Decker Inc; 2004. p. 665-74.

3. Grillo HC, Wright CD, Vlahakes GJ, MacGilivray TE. Management of congenital tracheal stenosis by means of slide tracheoplasty or resection and reconstruction, with long-term follow-up of growth after slide tracheoplasty. J Thorac Cardiovasc Surg. 2002;123:145-52.

4. Rishavy TJ, Goretsky MJ, Langenburg SE, Klein MD. Anterior bridging bronchus. Pediatr Pulmonol. 2003;35:70-2. 